\title{
Teoría Pedagógica
}

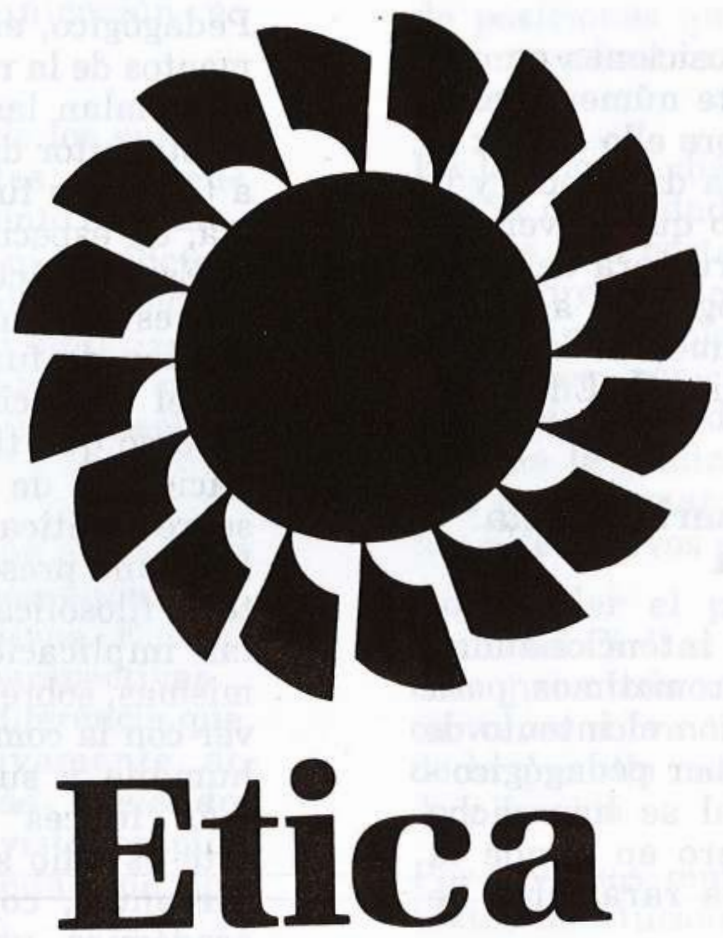

\section{$\mathbf{y}$ \\ educación}

\section{Alberto Martínez Boom y * Alfonso Tamayo Valencia **}

$\mathbf{A}$ nte la reiterada denuncia de una crisis de valores y la abundancia de soluciones salvadoras para esa misma crisis, vale la pena arriesgar y explorar otra posibilidad que vaya en contravía de las explicaciones funcionalistas que se orientan a señalar los profundos vacíos del estado y a formular lo que este debería ser; y de las posiciones intelectualistas que pretenden dar cuenta del conflicto estableciendo una comunidad ideal de habla enmarcada en normas comunicativas objetivas y universales.

\section{Crisis social o crisis de} valores?

Se trata de repensar la relación entre la razón y el mo- mento histórico que vivimos, analizar como lo hizo Kant en su época, la coyuntura histórica particular que nos cons-

- Alberto Martínez Boom. Investigador Programa de Investigación, Historia de la Práctica Pedagógica en Colombia.

** Alfonso Tamayo Valencia. Profesor Universidad Pedagógica y Tecnologica de Colombia. Facultad de Educación. Tunja. 
tituye, e intentar responder a ella. Elaborar una ontología crítica de nosotros mismos.

Más allá de las angustias existencialistas por la pérdida del sentido y las preocupaciones por el desmoronamiento cultural y social, es preciso recuperar la pregunta crítica por la racionalidad que hasta ahora nos ha atrapado y reconocer el agotamiento de un modelo fundado en verdades absolutas y universales sobre la naturaleza humana y en la autoridad de la religión y la metafísica.

"La ontología crítica de nosotros mismos no debe considerarse como una doctrina, como una teoría, ni siquiera como un permanente cuerpo de conocimiento que se está acumulando; se le debe concebir como una actitud, un ethos, una vida filosófica en que la crítica de lo que somos es en uno y al mismo tiempo el análisis histórico de los límites que nos imponen a nosotros y un experimento con la posibilidad de ir más allá de ellos"1.

Pensamos con Foucault que es posible proceder de otra manera: proceder a partir de un ethos que renuncia a la guía de la religión, la ley y la ciencia, mientras renuncia también al empeño de realizar la verdad profunda del yo que ellas fomentan, cada una a su manera. Este nuevo gesto, esta nueva actitud se mueve en dos frentes: el trabajo con uno mismo y la respuesta a la época de uno abren la posibilidad de un espacio ético diferente.

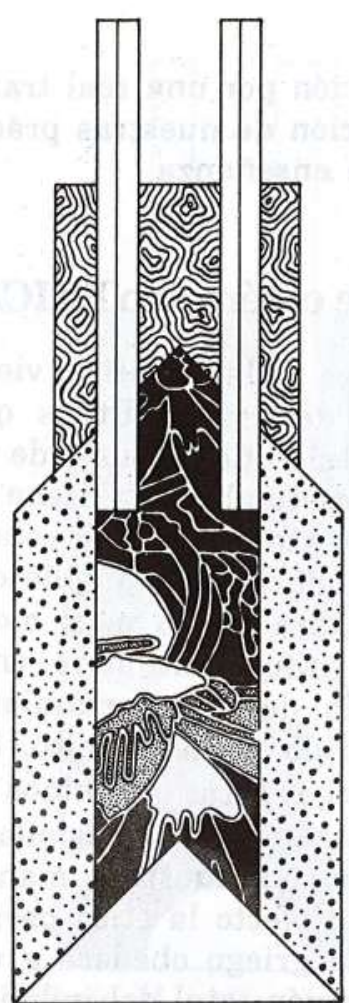

Asumir lo ético como el "cuidado de sí" y enfrentar con madurez los peligros específicos que genere el hecho de haber privilegiado en la cultura occidental el "conocimiento de sí mismo" desde la ciencia, la ley o la religión, con toda la carga de "poder" que este "saber" implica. No se trata de una analítica de la verdad que desenmascara el poder sino del reconocimiento de que toda verdad es poder.

Movernos entre la modernidad y la madurez que como lo señala Couzens ${ }^{2}$ "no es un acontecimiento histórico específico sino una coyuntura histórica que ha sucedido varias veces en nuestra historia, si bien con diferente forma $y$ contenido: derrumbe de las virtudes tradicionales en Atenas en la época de Sócrates, la declinación del mundo Helénico, el fin de la metafísica en la época de Kant. Este derrumbamiento resulta de una específica actitud hacia la realidad que, para diferenciarla de un estado subjetivo, Foucault denomina Ethos".

Consideramos que nuestra crisis es una crisis de modernidad que sucede cuando una interpretación de la realidad, dada por descontada deja de funcionar como transfondo compartido en términos del cual la gente puede orientarse y justificar su actividad, y la respuesta modernista es enfrentar heroica y lúcidamente el derrumbamiento del orden antiguo.

Pero no básta ser modernos, es preciso también movernos en la madurez que consiste, siguiendo a Couzens, "no solo en una actitud heroica sino también en una posición irónica hacia la situación presente de uno ... actitud irónica es un abandono de la tradicional seriedad mientras se mantiene el compromiso activo con las preocupaciones del presente... La posición irónica resulta de la búsqueda en el presente de esas prácticas que ofrecen la posibilidad de un nuevo modo de actuar"3.

Movernos entre la modernidad y la madurez consiste en enfrentar el derrumbamiento renunciando a la búsqueda de condiciones trascendentales

1 Couzens, Hoy "Foucault. Ediciones Nueva Visión. Buenos Aires, 1988. Qué es la madure»? Habermas y Foucault acerca de: "Qué es el Iluminismo". H. L. Dreyfus y P. Rabinow, p. 128.

2 Ibidem., p.133.

3 Ibidem., p.134. 
para un nuevo orden: ni dioses, ni paradigmas, ni consejos para la acción, solamente el diagnóstico del peligro contemporáneo y proporcionar los elementos para una nueva manera de dar cuenta de nosotros mismos, para una nueva actitud.

"La búsqueda de una forma de moralidad aceptable por parte de todos en el sentido de que todos deberían someterse a ella, me parece catastrófica" había dicho Foucault en una entrevista en 1984.

En suma, optar por esta línea de trabajo es mantener una integridad ética e intelectual que mientras se opone vigorosamente a las justificaciones de nuestras acciones en términos de religión, derecho, ciencia o fundamento filosófico, de todos modos trata de producir una nueva forma de vida ética que ponga en primer plano la imaginación, la lucidez, el humor, el pensamiento disciplinado y la sabiduría práctica.

Es esta una tarea de largo aliento que aquí solamente comenzamos, señalando la historicidad de "lo ético", la forma externa como se ha asumido y enseñado en los manuales cuyos propósitos claros o implícitos obedecen también a formas de poder a través del supuesto saber sobre la moral. Y mostrando como en la obra de Foucault existen suficientes elementos para pensar de otra manera, arriesgar una nueva actitud hacia lo moral para finalmente explorar la posibilidad de una nueva relación ética- educación por una real transformación de nuestras prácticas de enseñanza.

\section{Sobre el término ETICA}

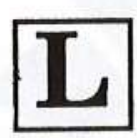

a palabra ética viene del griego Ethos que significa "modo de vivir", "costumbres", y tiene en el contexto griego una connotación mucho más amplia que la palabra latina mos: moris que significa costumbre, en el sentido del comportamiento adquirido por el hábito. Sin embargo estos términos se equiparan con demasiada ligereza, en nuestros manuales. En efecto la ética para el mundo griego obedece a una concepción total del individuo y la sociedad, de la virtud y la verdad, donde la eticidad estaba asociada con el "cuidado de sí" con la "preocupación por sí".

Este precepto era para los griegos uno de los principales principios para las ciudades, una de las reglas más importantes para la conducta social y personal y elemento fundamental en el arte de la existencia.

Esta noción se nos ha vuelto ahora muy oscura y desdibujada; la tradición filosófica y la espiritualidad cristiana han enfatizado el "conocimiento de sí" sobre el "cuidado de sí". Transformación profunda que en la moral de la sociedad occidental ha privilegiado el conocimiento de sí mismo cuyas consecuencias objetivan al sujeto, rechazan el sujeto y funda la moralidad en la negación de sí. "Somos herederos de una tradición secular que respeta la ley externa como fundamento de la moralidad... una moral social que busca las reglas de la conducta aceptable en sus relaciones con los demás"4.

Por este motivo resulta dificil considerar el interés por uno mismo como compatible con la moral.

La eticidad alude en Grecia al hecho de asumir la existencia como articulada al todo social y como viviendo la tensión fundamental entre la ley y la conciencia moral individual. Tiene un carácter trágico en el sentido griego que, como lo ejemplica Hegel se sucede cuando se enfrentan por un lado la conciencia individual y las exigencias sociales con igual potencia y sin que encuentren una síntesis ${ }^{5}$.

Asumir la existencia desde la eticidad es, en este contexto, poder dar cuenta de sí mismo, renunciando a todo dogmatismo, perdiendo toda seguridad fundada en la autoridad o la tradición, el mito o la religión y enfrentando la búsqueda de la verdad por sí mismo apoyados en la lógica y en la crítica. Implica también, como nos lo dice E. Zuleta ${ }^{6}$ reinvindicar la libertad de acción como resultado de la libertad de pensamiento, libertad de acción que pone como requisito para acatar las leyes el que uno mismo las

4 M. Foucault. Tecnologias del Yo UDEBA - Barcelona 1990 - pág. 45.

5 Zuleta Estanislao Arte y Filosofia Ed. Percepción. Medellín, p.25.

6 Ibidem., p.22 
considere justas. La ética está pues en Grecia dentro del ámbito de lo que se ha considerado como la Paideia ${ }^{7}$. No hay allí división entre pensar y actuar. La libertad de pensar nos lleva a la verdad y es ella la que pone como único criterio de saber la demostración lógica. "La libertad nos hace verdaderos en lugar que la verdad nos haga libres"8.

Por eso no es totalmente exacto equipararla al concepto mos-moris que en el contexto romano, latino y luego en el cristianismo va a adquirir un carácter individual, que tiene que ver más con el acto realizado con conocimiento y libre decisión en lo que compete a la esfera de la conciencia individual (en relación con un "código moral" externo que sirve como referencia para guiar el comportamiento).

No es lo mismo pues hablar de ética en la Grecia del siglo IV que de moral en la Edad Media o en el contexto romano. Son formas de vida diferentes; mientras la primera tiene todas las condiciones para el ejercicio libre de la razón, en la Edad Media es la exigencia del ajuste al legislador divino, a la palabra revelada, a la autoridad de la iglesia, lo que diluye al individuo en una moralidad asumido dentro de una visión teocéntrica.

Conviene señalar cómo, desde el aprovechamiento por parte de la iglesia del vacío cultural y de conocimiento ocasionado por la caída del imperio romano, la ética se equipara con la moral y ésta se confunde con la moral cristiana. En la Edad Moder-

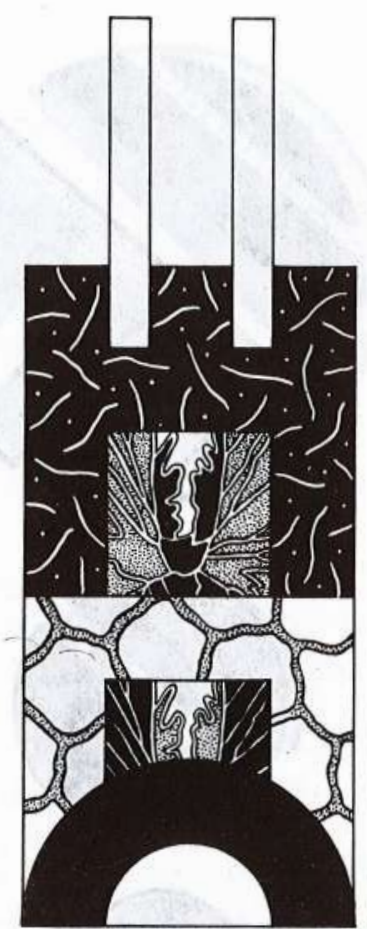

na y bajo el embrujo arrollador del modelo científico de Bacon y Galileo, de Kepler y Newton, la ética aparece como una "ciencia de la moral" y las preguntas acerca del bien y sobre el criterio de acción moral, comienzan a tratarse como si fueran objetos físicos, tendencia ésta que va a ser denunciada por G. Moore como la "falacia naturalista" que confunde el deber ser con el ser'. El aporte de la filosofía analítica en el siglo XX consistirá en mostrar el error lógico que se comete cuando se trata de buscar "el bien" como si fuera un hecho y el reconocimiento de que son las opciones morales las que pueden recibir el juicio de valor, que expresado en proposiciones. solamente puede ser utilizado desde el lenguaje, dando pie a una meta-ética que analiza el lenguaje y deja la puerta abierta al intuicionismo 0 al emotivismo, cuando no a una forma velada de excepticismo como se insinúa en L. Wittgenstein: "La ética es indecible", "en el mundo no hay ningún valor", "la ética es trascendental", "de lo que no se puede hablar lo mejor es callar"10.

Esta excursión rápida y superficial sobre la connotación del término no tenía otra intención que la de señalar la historicidad de la ética y el devenir de su discurso y nos permite concluir que no es ella la pregunta por esencias o substancias de lo moral que nos lleve à la afirmación de un "algo" inmutable y perenne sino que también esta noción, como todas las nociones del lenguaje es construcción social. Y no está predeterminado de antemano sino que se legitima en el uso que se le da.

\section{La ética de los manuales}

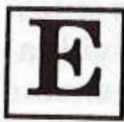
n los manuales, la ética se asume como disciplina y como cien cia $^{11}$, se le designa como teórica, como sistemática y objetiva, como estudio sobre el hecho moral, con lo cual se legitima más la división iteóricopráctica, hecho-valor, razón pura y razón práctica, reduciéndola pues, a un ejercicio académico que nada tiene que ver con nosotros y que sola-

7 Ch. Jaeger. Paideia. FCE. México.

8 Zuleta, E Op. cit., p.21.

9 Moore, Gorge. Etica. Edit. Labor. Barcelona. 1929, p.8.

10 Wittgenstein, Luduwig. Tractatus Logico-philosophicus. Ed. Revista de Occidente. Madrid. 1957, pp. 185-191.

11 Sánchez Vasquez, Adolfo. Etica Edit. Grijalbo. México, 1986. 
mente está orientado a saber datos, personajes y corrientes que han pensado sobre lo moral y de los cuales debemos dar cuenta en los exámenes.

Nos quedamos entonces con un inventario o recetario de máximas de acción moral al cual debemos acoger nuestras propias acciones y hasta pretendemos elaborar desde allí una deontología o código de prescripciones para nuestra profesión que, a la manera de los diez mandamientos, nos permitirán definir quién es mejor o peor profesional mediante la aplicación de una fórmula abstracta y general que nos dice "sea responsable, sea honesto, sea solidario", sin preguntarse por las mil y una formąs como esa prescripción es asimilada o por las condiciones de posibilidad de la misma norma, o sencillamente sin pensar en la posibilidad de que por cuestión de principios individuales esas mismas exigencias no sean acatadas.

El problema social pretende solucionarse mediante una campaña de moralización, la instalación de cursos de ética profesional en las universidades y la cátedra de democracia en el bachillerato, orquestada por la gran prensa que señala tendenciosamente la pérdida de valores como si éstos estuvieran sustancializados en algún lugar y el esfuerzo de la sociedad se debiera encaminar a rescatarlos, ponerlos en vigencia, "alimentarlos en casa", convirtiéndose esta campaña en una cruzada por la moral y las buenas costumbres que

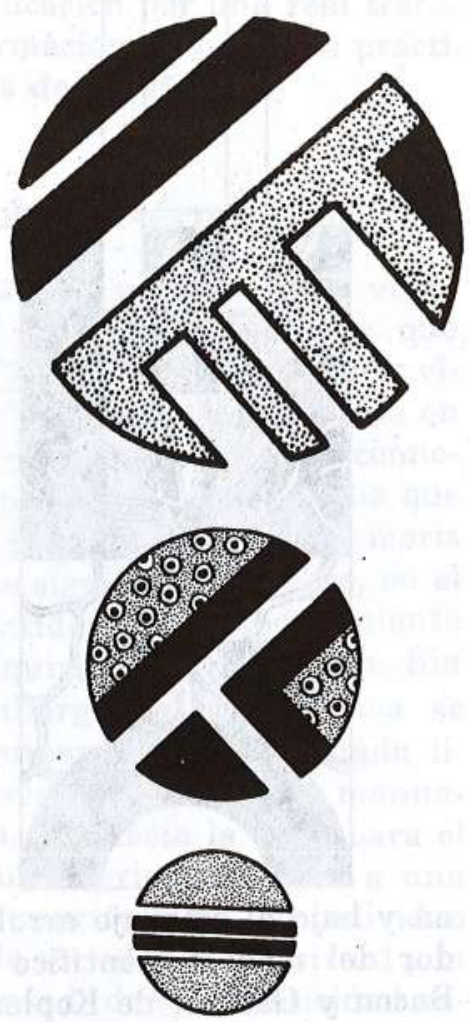

añora el Manual de Urbani. dad de J. M. Carreño, el Catecismo del padre G. Astete, y mayor autoridad de padres y maestros, de jueces y policías.

Ante tal estado de cosas se mira hacia la educación y se pide a los maestros que formen a los niños para la paz, que enseñen la tolerancia, que sean responsables y obedezcan la autoridad, que lideren procesos de democracia y se conviertan en ejemplo de buenas costumbres y moral, que hable de los valores eternos y los inculque a los niños. Hay pues unos valores, que de acuerdo con esta perspectiva deben recuperarse, valores que siempre han estado ahí y con los cuales el maestro debe comprometerse ${ }^{12}$. De este modo y a partir de esta particular relación, se definen espacios y metáforas según las cuales la educación se compromete con la reproducción de los valores.

Desde hace tiempo nos bombardean con manuales que dan teorías para el perfeccionamiento de uno mismo. Se instaura así en universidades y colegios una práctica de saber que podríamos llamar de "neutralidad valorativa" acerca de la ética y que aparentemente nada tiene que ver con nosotros, ni con nuestros intereses, ni con nuestras formas de vida. Pero que obedece a toda una estrategia de poder que nos atrapa y nos impone sus normas.

Nos hacemos eruditos, pero no mejoramos nuestra estética de la existencia.

No es pues lo fundamental el establecimiento de recetas, ni mucho menos un problema de definiciones. Por el contrario, la pregunta fundamental es por el momento de gestación de esas formas de saber y poder que nos han sujetado $y$ al mismo tiempo las formas y las modalidades de la relación consigo mismo por las que el individuo se constituye y se reconoce. Su análisis nos permitirá constatar que así como tuvieron un comienzo también pueden tener un final y que así como un punto de partida fue desarrollándose hasta convertirse en paradigma de enseñanza y manera

12 Revista Educación y Cultura No.16. Oct. de 1988. "Educación y derechos humanos". FECODE. 
de pensar la ética, también podemos retomar el origen para embarcarnos en una nueva aventura de pensamiento y acción que nos permita otra manera de estar en el mundo y de proceder en el discurso.

En un interesante trabajo ${ }^{13}$ se ha demostrado que la enseñanza de la ética que predominó hasta los años 60 en los manuales de Filosofía "es teocrática y establece una jerarquía de los bienes en cuya cúspide está la iglesia, lo espiritual y después en orden descendente desde lo absoluto, hasta la escoria, se pueden clasificar lo social, lo individual, lo material... La existencia de una moral única, inmutable, universal y homogénea, impide el reconocimiento de la historia humana"... Todas las filosofías modernas y contemporáneas, son rechazadas a nombre de la moral". "Las teorías de las ciencias humanas son aniquiladas por conducir a diversos absurdos, a las "contradicciones", al "relativismo" a la "inmoralidad", al "historicismo", al "comunismo", al "liberalismo", al "materialismo", al "modernismo", al "protestantismo" y, a eliminar la supremacia de la iglesia sobre el Estado. $\mathrm{Al}$ parecer, esta enseñanza escolar, antes que pensar, contrapiensa para oponerse a sus enemigos". Es preciso entonces ensayar otro modo de pensamiento o mejor liberarnos de un viejo esquema que, como diría L. Wittgenstein "mantiene la mente en una posición rígida, la entumece y nos obliga a ver las cosas

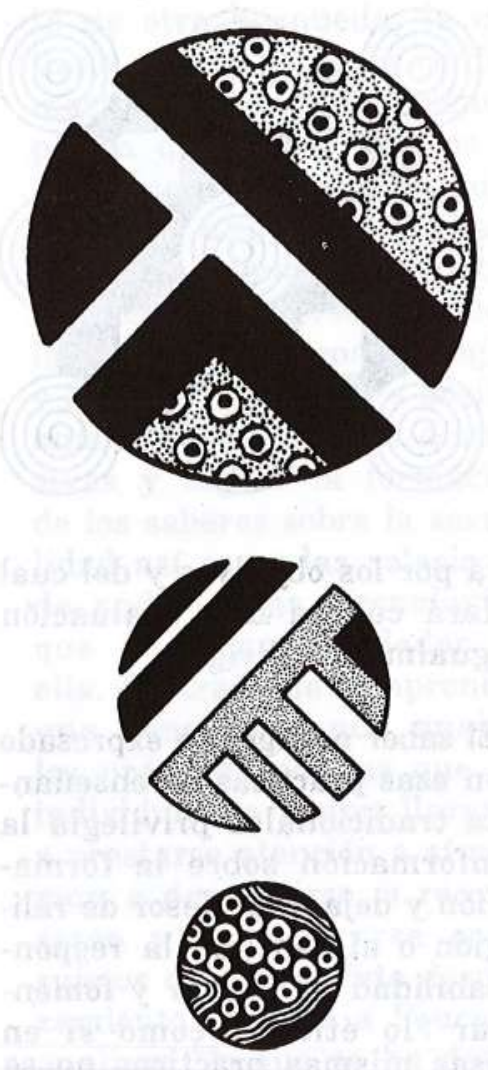

siempre de la misma manera"14.

Se trata de hacer una primera incursión en este campo para delinear los elementos fundamentales de un proyecto de largo aliento que promueva nuevas formas de interrogación sobre lo ético y las inscriba en una nueva manera de ver.

\section{Hacia una ética como práctica de sí}

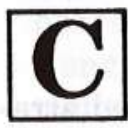
on Foucault podemos decir que el individuo siempre ha estado su jetado por diversas formas de saber y poder desde donde se le anticipa una condición de sujeto y se le monta todo un dispositivo que desde "la verdad" o desde "la normalidad" pretenden instaurar una legitimidad epistemológica y una mirada panóptica que declara lo que se puede y lo que no se puede en una formación social dada.

Sus trabajos sobre la Arqueología del Saber develaron la génesis de estas formas de saber y mostraron los paradigmas desde los cuales se monta todo este aparato discursivo que revela, esconde, disimula o normatiza en un poderoso proceso de reiteraciones, rupturas o. positividades que amarran a determinados esquemas verbales que a su vez son expresión de práctica de saber, de enseñanza, de información, que permiten identificar formaciones discursivas, institucionales y sujetos inscritos en esas mismas prácticas y determinados por esos mismos dispositivos. Para el caso de la enseñanza, la aplicación de esta arqueología del saber pedagógico nos permitió denunciar el enrarecimiento de la pedagogía por el auge de las llamadas ciencias de la educación que como la psicología, la sociología, la administración, la economía o la antropología se apropian del sujeto, de los procesos de enseñanza o de las instituciones reduciendo así al maestro a un mero administrador., aplicador de instrumentos o en el peor de los

13 Londoño, Carlos A. El discurso reactivo de la enseñanza escolar de la filosofta. En Revista Educación y Ciencia. Quinta época. Año I No.I. Febrero 1985. Tunja. Boyacá. Colombia, p.50.

14 Wittgenstein, Ludwig. Cuadernos Azul y Marron. Edit. Tecnos. Madrid. 1976, p.92. 
casos en "un peregrino de su saber $y$ en un mendigo de su salario"15.

Queda pues sujetada la enseñanza a estas formas de "saber pedagógico" y el maestro y el niño, la institución y la sociedad atrapadas en esta red de relaciones que niegan la identidad del maestro, lo descentran de su fundamento pedagógico y convierten la enseñanza en un mero proceso de aprendizaje que nada tiene que ver con el pensamiento, el lenguaje, la cultura y la sociedad.

Desde esta primera instancia de sujeción la ética aparece igualmente desconocida ya que lo que interesa es la información, la erudicción, la profesionalización, el conocer especializado o particularizado en cada una de las asignaturas, realizado a través de prácticas de enseñ̉anza que nada tienen que ver con la fundamentación teórica ni con la construcción práctica de un proyecto de vida sino con la mera repetición, memorización y rutina en un ritual de "saber dictar clase" que repite hasta el cansancio unas formas vacías de "motivación, introducción, afianzamiento, evaluación y tarea para mañana" sin la fundamentación pedagógica y ética que este mismo les dió ya para el siglo XIX en su "Pedagogía General"16. Y de otra parte de transmisión de contenidos para el aprendizaje previamente seleccionado por el maestro según las exigencias de los programas y con un control directo de su proceso de asimilación que se media-

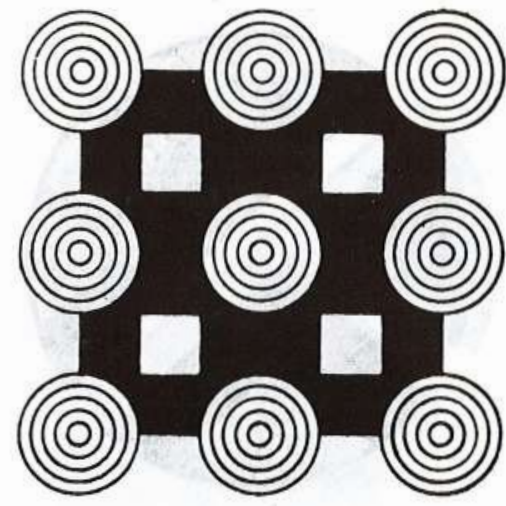

rá por los objetivos y del cual dará cuenta una evaluación igualmente dirigida.

El saber pedagógico expresado en esas prácticas de enseñanza tradicionales privilegia la información sobre la formación y deja al profesor de religión o al capellán la responsabilidad de pensar y fomentar "lo ético"... como si en esas mismas prácticas no se estuviera de hecho expresando un mundo de valores y una moralidad, que sin embargo no es explícita ni tematizada en la enseñanza.

También desde el poder el individuo es sujeto, deviene humano por su ubicación en esa complicada red de vigilancia y castigo, de normalidad y patologías que instaura también un dispositivo de coersión que determina a todo individuo, lo sujeta a su red y lo marca, lo mira, lo determina y lo vigila.

En la educación esta red atrapa al individuo y a las instituciones a través de los reglamentos, los manuales, la disciplina, la administración, la legislación escolar, que normatiza sobre las conductas deseadas, castiga y discri- mina respecto a lo normal. Cárceles, hospitales y manicomios dan cuenta de los que están enfermos, no son sanos, y desde este ejercicio del poder se afinan mil formas de sujeción que instaura también una mirada sobre el cuerpo y el alma, mirada dualista que reparte entre el poder terrenal y el poder divino a los sujetos quienes se formarán como buenos ciudadanos para el gobierno y como cristianos para la iglesia.

En nuestra educación, el trabajo de Humberto Quiceno ${ }^{17}$, sobre la "Pedagogía Católica y la escuela activa en Colombia" ha revelado ya todos estos aparatos de vigilancia y castigo, de control y hegemonía. A través de las comunidades religiosas la educación se convierte en un proceso de sujeción que mata la autonomía, que instaura el dogmatismo y la intolerancia, que sospecha morbosamente del deseo y su realización, que desprecia el cuerpo y considera al niño como un perverso. A nombre de la moral cristiana se arma toda una cruzada santa contra cualquier forma de enseñanza laica, que proponga la separa-

15 Zuluaga, Olga Lucía. "El trabajo histórico y la recuperación de la práctica pedagógica". En: Revista Educación y Cultura. FECODE. Bogotá. No.3, marzo 1985, p.68.

16 Herbart, Juan F. Pedagogia general. Ediciones de la lectura. Madrid. sf.

17 Quinceno, Humberto. Pedagogia Catolica y Escuela activa en Colombia. Edit. Foro Nacional por Colombia. Bogotá. Marzo 1988. 


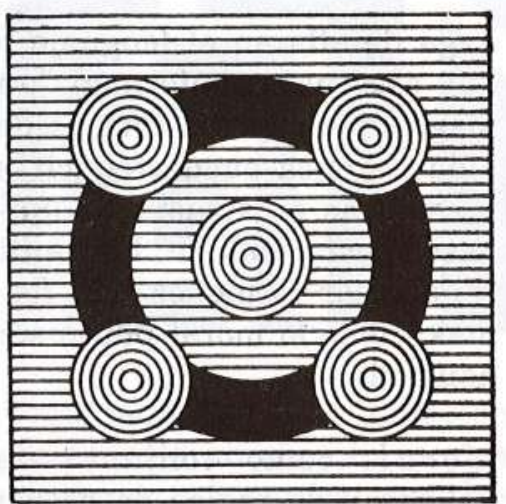

ción de la iglesia del Estado y que se abra a un sano pluralismo en el conocimiento y en las prácticas religiosas.

Queda claro que en la obra de Foucault la pregunta por la génesis de estas formas de sujeción permite también pensar que las cosas pudieron ser distintas: la ciencia nos sujeta y determina lo que debemos pensar y cómo debemos buscarlo. La religión y el derecho nos determinan también regulando las formas de convivencia y estableciendo lo que debemos creer y obedecer. Estamos entonces cruzados por múltiples determinaciones a las cuales no es posible escapar y cuyo influjo inevitablemente debemos reconocer. ¿Quién es el sujeto?, ¿dónde quedó la autoconciencia de sí que de manera orgullosa pregonó el racionalismo con Descartes a la cabeza?; ¿qué fue de ese cogito sustancial y diferente de las cosas extensas? ¿dónde quedó la libertad?.

Pero las prácticas de sujeción no terminan ahí. También el deseo es controlado, seleccionado, aprobado o negado, censurado o valorado: en su obra "Historia de la Sexuali-

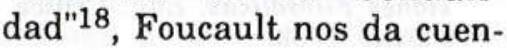

ta de otra búsqueda, la que tiene que ver con la conformación de una experiencia por la que los individuos se van reconociendo como sujetos de una "sexualidad" abierta a dominios de conocimiento muy diversos y articulada con un sistema de reglas y de restricciones". Es posible analizar las prácticas discursivas y seguir la formación de los saberes sobre la sexualidad así como las relaciones de poder $y$ las tecnologías que se crean alrededor de ella. Se trata de "emprender una genealogía que analice las prácticas por las que los individuos se vieron llevados a prestarse atención a sí mismos, a descubrirse, a reconocerse y a declararse como sujetos de deseo. Este desplazamiento permite a Foucault analizar "lo que se ha designado como "el sujeto"; convenía buscar cuáles son las formas y las modalidades de la relación consigo mismo por las que el individuo se constituye y se reconoce como sujeto"19. Y su estudio nos permite a nosotros situar la pregunta por la ética que determine como el individuo simplemente se constituye como sujeto moral de su propia acción.

No se trata entonces de normatizar desde otra moral o de hacer un aporte teórico a la ciencia de la ética ni mucho menos prescribir lo que sería una ética de la educación ... se trata tan sólo de describir las formas como el individuo deviene sujeto y pensar algunas consecuencias que esta descripción tiene para la educación.

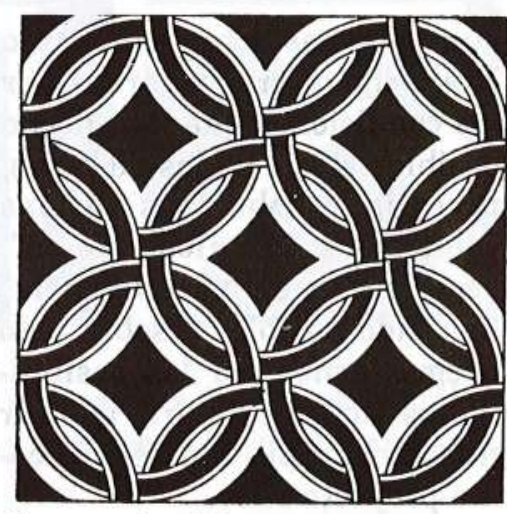

Pensar la ética como un verdadero arte de la existencia, "entendido como aquellas prácticas que de una manera sensata y voluntaria han permitido que el hombre se fije reglas de conducta, busque transformarse a sí mismo, modificar su ser singular y hacer de su vida una obra que presenta ciertos valores estéticos y responde a criterios de estilo"20.

Conviene detenernos un poco en esta concepción de la ética:

Tanto en los griegos de la antigüedad, como en las formulaciones ya clásicas de la ética se ha insistido de manera práciica y teórica en que el campo propio de la eticidad es la acción humana desde la voluntad y el conocimiento. Acción moral se le ha llamado y sobre ella se han construido sistemáticamente estudios denominados de ética. Sin embargo, y este es un aporte de Foucault, no solo debemos hacer una historia de los comportamientos o de lo

18 Foucault, Michel. Historia de la Sexualidad Tomo II. Siglo XXI. México, 1986.

19 Ibidem., p.7.

20 Ibidem., p.14. 
que sabemos sobre ellos sino ir al origen: preguntarnos por las condiciones que han hecho posible estos estados de cosas, investigar sobre las formas como esıs "técnicas de sí", esas "artes de la existencia" han sido posibles y sobre todo preguntarnos por las posibilidades actuales para asumir nuestra propia existencia como proyecto ético.

De manera somera podemos recordar como Foucault que esas prácticas de sí, tan valoradas entre los griegos de la antigüedad para quienes la existencia es asumida trágicamente ${ }^{21}$ y en ella se vive tanto la angustia de pensar por sí mismo, sin dogmas ni verdades absolutas, como la angustia de ser consecuente con lo que se piensa, aunque vaya en contra de lo establecido, de lo legal, de lo manda$\mathrm{do}^{22}$ como bien nos lo explica E. Zuleta, ya no son tan valiosas una vez integradas al cristianismo y articuladas al ejercicio de un poder pastoral y más tarde a prácticas de tipo educativo, médico o psicológico. Podriamos arriesgar aquí la hipótesis de que después de los griegos lo ético se diluyó en múltiples formas de sujeción desde el poder, el saber o el deseo y diversas disciplinas e instituciones se encargaron de legitimar esta pérdida. El esquema sencillo de pensar libremente y actuar libremente como resultado de asumir la existencia como una tensión permanente entre lo legislado, lo social, lo externo y lo dictado por la conciencia moral, lo individual, lo que se piensa por sí mismo, trastocado por múlti- ples formas de conformismo, de adecuación a intereses, de facilismo. Si esta hipótesis tuviera alguna acogida entonces el "elogio de la dificultad" del maestro Zuleta tendría plena vigencia.

Es pues a partir de las "prácticas de sí" como puede uno dar cuenta de las problematizaciones éticas más allá de la pretensión de los manuales de hacer una historia de los sistemas de moral.

Abordar con Foucault la pregunta por la moral es atreverse a pensar de manera diferente respecto de ella y seguirlo en los métodos y propuestas de análisis, trabajo de largo aliento que tendremos que emprender algun día, en este ensayo solamente queremos relievar el aporte de Foucault en la consideración de la moral práctica de $s^{23}$ y sacar algunas conclusiones en lo pedagógico:

\section{Moral y práctica de sí}

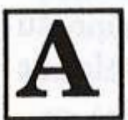
A pesar de las historias de la moral y de lo mucho que se ha escrito sobre la moralidad como objeto de la ética es preciso replantear esta mirada y recomponer este estado de cosas. El aporte de Foucault muy cercano a L. Wittgenstein aquí, es reconocer los múltiples usos de la palabra "moral" y las diferentes prácticas que ella encierra. A la manera como L. Wittgenstein insiste en que el significado de una palabra lo da el uso que se haga de ella en el lenguaje y que esos usos conforman "un juego" que expresa formas de vida y nunca puede reducirse a esencias o estructuras úni$\operatorname{cas}^{24}$, así también Foucault señala por lo menos tres formas como lo moral puede ser asumido:

Moral: como conjunto de valores y de reglas de acción que se proponen a los individuos y a los grupos por medio de aparatos prescriptivos diversos, (familia-iglesia-escuela). Moral: como el comportamiento real de los individuos en su relación con las reglas y valores que se les proponen. Moral: como la manera en que debe constituirse uno mismo como sujeto moral que actúa en referencia a los elementos prescriptivos que constituyen el código.

Estas diferencias pueden apoyarse en muchos puntos, nos dice Foucault, convienen a lo que podríamos llamar la $D e$ terminación de la sustancia ética, es decir la manera en que el individuo debe dar forma a tal o cual parte de sí mismo como materia principal de su conducta moral, (reglas, deseos, sentimientos). Conviene también al modo de sujeción, es decir a la forma en que el individuo establece su relación con esta regla y se reconoce como

21 ZULETA, Estanislao.Op. cit., p.19.

22 Ibidem., p.20.

23 Foucault, Michel. Op. cit, p.26.

24 Wittgenstein, Ludwig. Investigaciones Filosoficas. Edit. Critica. México. 1988. 

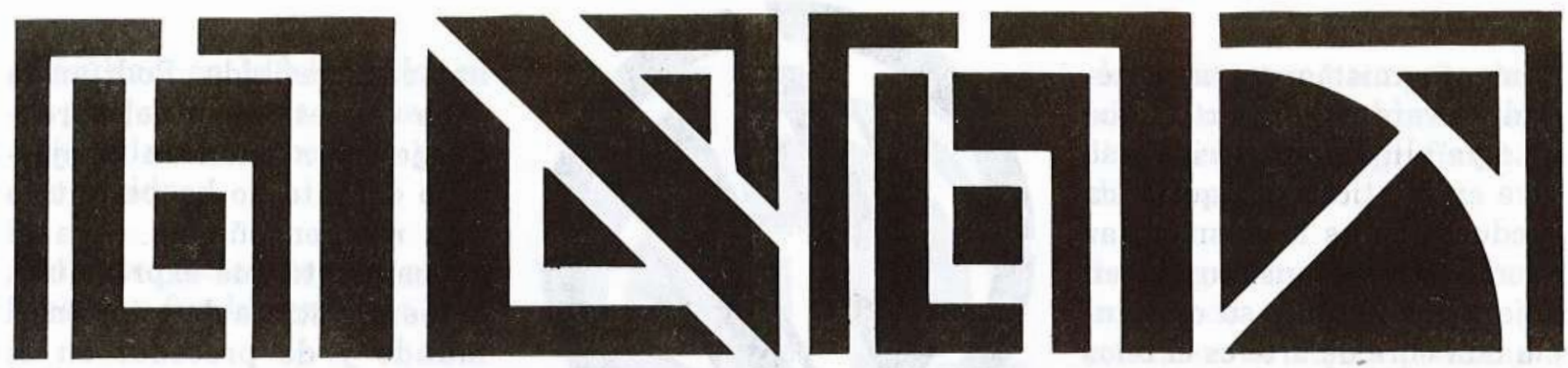

vinculado con la obligación de ponerla en obra (o sea los motivos y razones por los cuales un individuo practica, por ejemplo la fidelidad conyugal).

Las diferencias tienen que ver también con las formas de elaboración del trabajo ético que realizamos en nosotros mismos y no sólo para que nuestro comportamiento sea conforme a una regla dada sino para intentar transformarnos nosostros mismos en sujeto moral de nuestra conducta.

Otras diferencias conciernen a lo que podríamos llamar la teleología del sujeto moral: ya que una acción no solamente es moral en sí misma y en su singularidad, también lo es por su inserción y por el lugar que ocupa en el conjunto de una conducta; es un elemento y un aspecto de esta conducta y señala una etapa en su duración, un progreso eventual en su continuidad. Una acción moral tiende a su propio cumplimiento; pero además intenta, por medio de éste, la constitución de una conducta moral" 25 .

"Cierto que toda acción moral implica una relación con la realidad en donde se lleva a cabo y una relación con el código al que se refiere, pero también implica una determinada relación consigo mismo; ésta no es simplemente "Conciencia de sí", sino constitución de sí como "sujeto moral", en la que el individuo circunscribe la parte de sí mismo que constituye el objeto de esta práctica moral, define su posición en relación con el precepto que sigue, se fija un determinado modo de ser que valdrá como cumplimiento moral de sí mismo, y para ello actúa sobre sí mismo, busca conocerse, se controla, se prueba, se perfecciona, se transforma. No hay acción moral particular que no se refiera a una conducta moral; ni conducta moral que no reclame la constitución de sí misma como sujeto moral, ni constitución del sujeto moral $\sin$ "modos de subjetivación" y sin una ascética o "prácticas de sí" que los apoyen" 26 .

Los estudios que pretendan dar cuenta de la moral o de su relación con la educación tienen que partir pues del reconocimiento de esta complejidad: los códigos, las moralidades, los sujetos de conducta moral, y en general "toda forma de subjetivación moral y de las prácticas de sí que están destinadas a asegurarla"27. Código y ascesis son los dos polos sobre los que se han constituido los modelos éticos pero esta relación es compleja y reviste múltiples formas.

\section{Etica y Educación:}

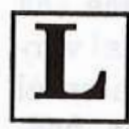
a relación Etica-Educación se ha planteado, en los últimos tiempos, desde la exterioridad, ya sea la de los manuales o desde las normas, aisladas de su contexto vital y social.

Se ha descentrado así el fundamento de la relación o mejor la relación misma: la educación es un proyecto ético.

Así podemos constatarlo en los griegos donde la relación que el maestro establece con el discípulo es diálogo permanente, tomándolo en serio y exigiéndole, incitándolo, en un ejercicio del preguntar que se convierte en todo un arte: la mayeútica. Allí no hay dogmas, la búsqueda de la verdad es la misma búsqueda de la virtud. El logos no es la mera inquietud por el saber, no es sólo el deseo sofista de erudición y retórica sino el horizonte iluminador desde donde la vida individual y social tienen sentido o mejor el fun-

27 pidem. 
damento mismo de la sociedad, la verdad y la virtud que está ya allí en el interior y se vive en la eticidad. Aquí ética y educación es lo mismo: dar cuenta de sí, constituirse en sujeto que hace de su existencia una obra de arte es el telos de la enseñanza.

Pero con el advenimiento de la moral romana y del cristianismo se instaura una escisión, desaparece el diálogo y se olvida la mayeútica. El maestro habla desde la verdad, el logos está afuera en el dogma. El discípulo no pregunta, escucha, permanece silencioso. La condición para adquirir la verdad es el arte de escuchar.

La ética fundada en este logos exterior desarraiga al individuo. La ley, la religión, la ciencia serán sus paradigmas.

La religión le ordena desde el absoluto divinizado, lo que debe hacer. La ciencia le dice lo que debe saber. Y se funda así una mirada sobre el sujeto, sobre el "yo" que también desde el exterior lo convierte en objeto de estudio a la manera de los objetos de la ciencia. la psicología se ocupará de su comportamiento, la sociología le explicará las determinaciones a que está sujeto, la medicina le señalará sus límites y posibilidades genéticas y fisiológicas, la antropología le describirá como objeto cultural y sus diferencias étnicas.¿Qué le queda pues al hombre como posibilidad de "constitución de sí"?. La moralidad fundada en la obediencia a la ley y el cono-

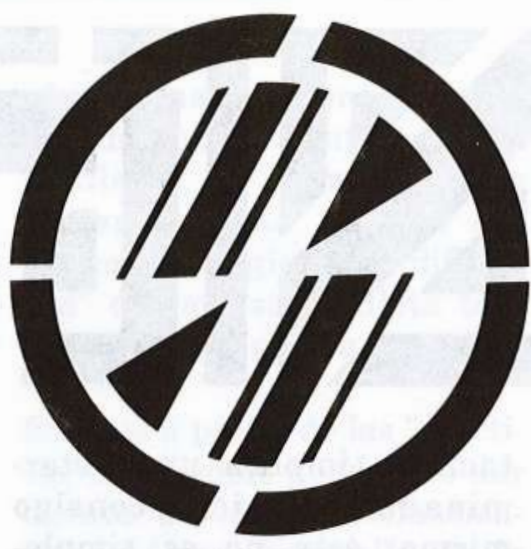

cimiento de sí positivisado en el "saber científico" construyen un sujeto que cuando vuelve sobre sí mismo es para inventariar sus culpas frente a una deontologia que lo juzga por lo que ha debido hacer y no hizo pero que no reconoce lo que ha logrado en su proyecto vital.

Recuperar esta relación perdida entre Pedagogía y Etica es pensar nuevas formas de enseñanza y volver a pensar también la finalidad misma de la educación.

La relación ética-educación ha sido pensada como la yuxtaposición de "algo" a "algo", ya sea la norma al acto, el principio a la acción, el imperativo categórico a la práctica, el deber ser al ser y esta forma de constituir el individuo en sujeto ha entrado en crisis.

Educar para la obediencia, para el conocimiento y reconocimiento de la autoridad en el orden del pensamiento, de la interacción social y en la política, ha sido un ejercicio legitimador del poder y del saber que constriñe el deseo, instaura la sumisión y el reconocimiento de la jerarquía entre los hombres como "naturalmente" dada o divi- namente recibida. Podríamos decir que esa ética del aprendizaje instaurada en el ejercicio docente no ha permitido una real enseñanza para el pensamiento que exprese una manera distinta de estar en el mundo y de proceder en el discurso.

Sin pretensiones moralizantes pero utilizando la filosofía como un martillo para destruir legitimidades que aparecen inamovibles por la fuerza de la costumbre o por la interiorización de la domesticación y para construir con imaginación y pasión alternativas posibles, que nos permitan inaugurar un "nuevo gesto", y asumir la educación misma como un ejercicio ético que expresa otra manera de pensar y por tanto de vivir consecuentemente con lo que pensamos. Apuntamos las líneas generales de un nuevo proyecto donde enseñanza, pensamiento, libertad y democracia, mediados por el lenguaje o mejor en el lenguaje como superficie de interacción simbólica e intercambio práctico, expresen un nuevo espacio ético donde la construcción de sí mismo, el reconocimiento del otro $y$ del respeto a la diferencia posibiliten un clima para el pensamiento propio, el reconocimiento de las culturas regionales y sobre todo la aceptación de la existencia propia como un proyecto cuyo sentido y significado se juega trágicamente en la cotidianidad asumida esta no como la búsqueda de seguridades sino como la práctica de una cultura del debate que nos permita vivir en el riesgo, en la 
dificultad, en la búsqueda, en la pregunta, pues solamente una vida así merece la pena ser vivida.

Este proyecto giraría sobre tres ejes fundamentales:
a) El pensamiento
b) El lenguaje
c) La democracia

\section{Enseñanza para el pensamiento.}

Consiste en la problematización de los conocimientos y de los saberes para abrir espacios que generen pensamiento creador para la cultura y las ciencias. Hay que partir de lo que tenemos, de lo que ya sabemos, pero no podemos quedarnos ahí ... es preciso sospechar de lo establecido, implantar la pedagogía de la pregunta, despertar la búsqueda, ejercitar el pensamiento. Asumir las verdades como resultados provisionales de procesos dinámicos y nunca como valores absolutos, dogmas o soluciones definitivas. Es reconocer que mediante el ejercicio de pensar podemos superar la inmediatez, lo evidente, el sentido común y salir de la falsa conciencia, de la representación sensible de la doxa o mera opinión. Es invitar a hacer un esfuerzo, doloroso, disciplinado, trágico, para renunciar a la seguridad de lo establecido desde la autoridad, la ley, la ciencia o la cultura y asumir el riesgo de construir nuestras verdades, pero no para cambiar a los demás sino para confrontar nuestros hallazgos con los de los otros en un

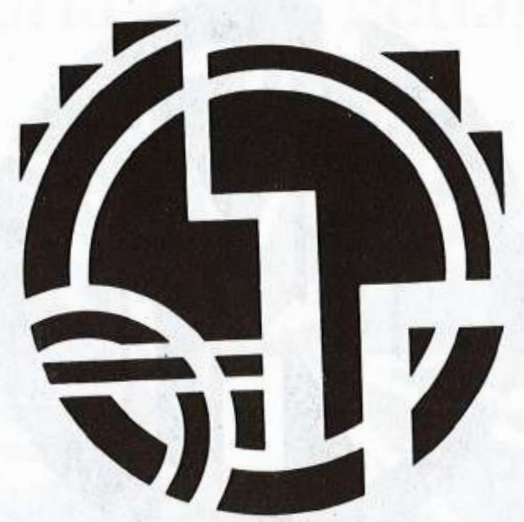

debate lógico y crítico que permita que la realidad y el mundo, el individuo y la sociedad sean conceptualizadas, comprendidas, explicadas en un intercambio productivo de diferencias y perspectivas. Es una nueva pedagogía que haga de la pregunta una vía a la investigación y de la enseñanza un concepto para replantear la cultura, el pensamiento, el lenguaje, la ética y la estética.

Pero no es tolerancia o escepticismo sino rigor en la discusión y exigencia de coherencia lógica, es en suma, hacer del pensamiento una actividad fundamental que pretende construir conceptualizaciones sobre la naturaleza y la sociedad, ejercicio dinámico y permanente que da sentido y significado al proyecto de existencia humana.

\section{La enseñanza de la lengua materna como vía al pensamiento}

La crítica hecha a la manera como la ética ha sido enseñada bien podría, análogamente, aplicarse a la manera como se nos ha enseñado la lengua materna: desde las reglas, las normas del buen decir, la gramática y la sintaxis, las grandes obras de la literatura, las biografías o los diccionarios.

La lengua materna se nos ha enseñado como un ejercicio analítico de sujeto predicados y verbos, de fonemas, morfemas, palabras, sílabas, juicios, raciocinios, argumentos, donde ha primado la estructura, lo esencial, la sintaxis o la prosodia, el estilo y las normas de la academia. Y por buscar la estructura olvidamos la riqueza y pluralidad, el polimorfismo y multiplicidad de formas de vida que se expresan en el lenguaje. Hablar una lengua es practicar un sistema de vida, el lenguaje es cultura y va más allá de la semántica. Es también pragmática, uso, vida.

El significado de una palabra es su uso en el sistema dinámico del habla donde ella cumple una función, sirve para algo y no solamente para relacionar una cosa con un nombre. El pensamiento se expresa en el lenguaje y viceversa: no hay pensamiento sin lenguaje, entendido éste como sistema de operación con símbolos hablados, escritos, gestuales, prácticos. Pero para pensar bien hay que leer y escribir bien; esto más que el conocimiento de reglas es una práctica, un uso permanente que amplía nuestro universo y nos permite construir simbólicamente el mundo, reconstruír la cultura, expresar el sentimiento, la emoción o la pasión, afinar la crítica o señalar la incoherencia. Somos lenguaje y éste 
puede adquirir mayor competencia para la expresión y la creación simbólica por medio de una nueva forma de enseñanza de la lengua materna que vincule lenguaje y vida, sociedad y expresión crítica, que muestre otras formas de leer y escribir y que no reduzca la lectura a la repetición en voz alta de los signos escritos ni la escritura a la reproducción en el papel de lo que otros han pensado.

Lectura y escritura de nuestra lengua como ejercicios para la construcción simbólica, la creatividad, la expresión de la imaginación y sobre todo para confrontar nuestro mundo cultural y social con otros que también lo han expresado en el lenguaje, en su"lenguaje", que no es mejor ni peor que el nuestro sino sencillamente diferente porque diferente es su forma de vivir.

\section{Enseñanza para la Democracia}

Pensar por sí mismo, expresarnos creativamente en el lenguaje, conlleva necesariamente a convertir la enseñanza en un espacio para el ejercicio de la democracia.

Asumimos aquí la palabra democracia en el sentido en que lo entendió E. Zuleta "diálogo entre iguales", relación de respeto por el otro tomándolo en serio pero acosándolo con argumentos, exigiéndole seriedad en el debate, otorgándole los mismos derechos que nosotros reclamamos para nosotros. "La función de la enseñanza en este caso no es indicar la solu-

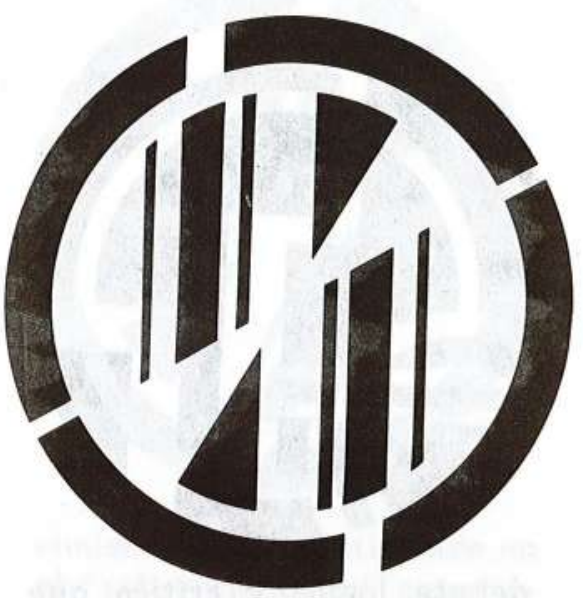

ción sino orientar, mostrar los diversos caminos. Se trata de no continuar patrocinando el paternalismo facilista. Se trata de desterrar el atractivo terrible de los paraísos y de las "vidas sin riesgo, sin luchas, sin búsqueda de superación y sin muerte. Y por lo tanto también sin carencia $y$ sin deseo: un océano de mermelada sagradá, una eternidad de aburrición"28. Otorgar al pensamiento algún lugar donde resistir, generar una cultura del debate que reconozca el derecho a la duda ... A partir del debate se abren condiciones de posibilidad para la duda capaz a su vez de generar espacios que nos ofrezcan la idea del pensamiento como un riesgo ... La nuestra es una cultura sin debate que dice sí y asiente porque no tiene nada en contrario que decir, sociedad atomizada y dispersa, violenta y competitiva, francamente opuesta a las posibilidades de un debate fecundo y a la tolerancia y reconocimiento del otro ... formarse en el conflicto $\mathrm{y}$ el debate para hacer de la cultura una trinchera, no sometida a esa diálectica del triunfo o de la muerte. Frente a esas diálecticas absolutas levantar las banderas de la diferencia ${ }^{29}$.

Se trata de proceder de otra manera como resultado de pensar diferente: El respeto al otro, la responsabilidad intelectual, la participación política, el respeto por la vida, la ética civil, la solidaridad, la amistad y el amor, son actitudes que expresan un ejercicio permanente, un cúmulo de actos donde estas mismas actitudes se expresan. Ver el mundo como un todo bello o asumirlo como un todo bueno no es un problema científico que pueda ser enseñado en contenidos de aprendizaje, es una posición personal ante el mundo que crece o disminuye según la altura o pequeñez de nuestras aspiraciones y deseos.

La enseñanza para la democracia más que una teoría piadosa o un código moral es la práctica de otra manera de vivir personalmente $y$ en so ciedad, es un nuevo gesto, una nueva actitud $y$ un nuevo compromiso. Pensar en la relación ética-educación es reconocer un estado de cosas y atrevernos a replantearlas, pues con Epicuro decimos "Si las cosas han sido así hasta ahora, podrían ser de otra manera".

28 Zuleta, Estanislao. Elogio de la dificultad. En: Sobre la idealización de la vida personal y colectiva y otros ensayos. Bogotá. Procultura. 1985, p.9

29 Martínez B. Alberto. Escuela para el aprendizaje o Enseñanza para el pensamiento Educación y Cultura No. 13 FECODE. Bogotá. Diciembre 1987, p. 55. 